\title{
Análise microbiológica e físico-química do leite produzido na cidade de Santana do Livramento - Rio Grande do Sul
}

\author{
Microbiological and physical-chemical analysis of millk produced in Santana do Livramento City - \\ Rio Grande do Sul
}

Análisis microbiológico y físico-químico de la leche producida en la ciudad de Santana do Livramento - Rio Grande do Sul

\author{
Deisi Dariane Rodrigues Arbello \\ ORCID: https://orcid.org/0000-0002-4725-6981 \\ Universidade Federal de Santa Maria, Brasil \\ E-mail: deisiarbello@icloud.com \\ Valéria Pinheiro Braccini \\ ORCID: https://orcid.org/0000-0002-6891-0196 \\ Universidade Federal de Santa Maria, Brasil \\ E-mail: valurug@bmail.com \\ Maximiliano Escalona Jiménez \\ ORCID: https://orcid.org/0000-0002-2516-4330 \\ Universidade Federal de Santa Maria, Brasil \\ E-mail:maximiliano.escalonaj@gmail.com \\ Magnólia Martins Erhardt \\ ORCID: https://orcid.org/0000-0003-3730-2515 \\ Universidade Estadual do Rio Grande do Sul, Brasil \\ E-mail: magnolia-erhard@uergs.edu.br \\ Neila Silvia Pereira dos Santos Richards \\ ORCID: https://orcid.org/0000-0001-6610-5567 \\ Universidade Federal de Santa Maria, Brasil \\ E-mail: neilarichardsprof@gmail.com
}

\begin{abstract}
Resumo
O leite é um produto rico em nutrientes e faz parte da alimentação da população. A produção leiteira no Brasil tem grande importância na economia, e as perspectivas de aumento de produção e consumo nos próximos anos são altas. O Rio Grande do Sul é um grande produtor, e boa parte do leite produzido no estado é oriunda das propriedades familiares e de sistemas de agricultura familiar. Devido ao grande consumo de leite e produtos lácteos é necessário que haja por parte dos produtores uma preocupação com a qualidade do leite produzido, visto que, atualmente os consumidores estão cada vez mais preocupados com a qualidade dos produtos consumidos, além disso, a questão qualidade é uma exigência da legislação e das indústrias. Para que isto aconteça uma série de requisitos de Boas Práticas Agropecuárias e de produção devem ser tomadas. Com isso o objetivo da pesquisa foi verificar a qualidade microbiológica e físico-química do leite produzido na cidade de Santana do Livramento-RS. Com os resultados obtidos podemos observar que em relação aos padrões físico-químicos quase que a totalidade dos produtores atendeu os parâmetros exigidos pela legislação. Em relação a Contagem Padrão em Placas, 73,33\% dos produtores possuem padrões de contagens baixas com valores $4.200 \mathrm{UFC} / \mathrm{mL}$ até $200.000 \mathrm{UFC} / \mathrm{mL}$, o que indica boas condições de higiene e de Boas práticas em seus processos. Conclui-se que o leite dos produtores analisados atende, em sua maioria, os requisitos físico-químicos e microbiológicos estabelecidos pela legislação, o que indica uma preocupação por parte destes produtores com qualidade.
\end{abstract}

Palavras-chave: Leite; Qualidade; Microbiológica; Físico; Química.

\begin{abstract}
Milk is a product rich in nutrients and is part of the population's diet. Milk production in Brazil has great importance in the economy, and the prospects for increased production and consumption in the coming years are high. Rio Grande do Sul is a large producer, and much of the milk produced in the state comes from small producers and family farming systems. Due to the large consumption of milk and dairy products, there must be a concern on the part of producers with the quality of the milk produced, since, nowadays consumers are increasingly concerned with the quality of the products consumed, in addition, the issue of quality it is a requirement of legislation and industry. For this to happen, a series of requirements for Good Agricultural and Production Practices must be taken. Thus, the objective of the research was to verify the microbiological and physical-chemical quality of the milk produced in the
\end{abstract}


city of Santana do Livramento-Rio Grande do Sul. With the results obtained, we can observe that in relation to the physical-chemical standards, almost all the producers met the parameters required by the legislation. Regarding the Standard Plate Count, $73.33 \%$ of the producers have low count standards with values of 4,200 UFC / mL up to 200,000 UFC / mL, which indicates good hygiene conditions and good practices in their processes. It is concluded that the milk of the analyzed producers meets, in its majority, the physical-chemical and microbiological requirements established by the legislation, which indicates a concern on the part of these producers with quality.

Keywords: Milk; Quality; Microbiological; Physical; Chemical.

\begin{abstract}
Resumen
La leche es un producto rico en nutrientes y forma parte de la dieta de la población. La producción de leche en Brasil tiene una gran importancia en la economía y las perspectivas de aumento de la producción y el consumo en los próximos años son altas. Rio Grande do Sul es un gran productor y gran parte de la leche que se produce en el estado proviene de pequeños productores y sistemas de agricultura familiar. Debido al gran consumo de leche y productos lácteos, debe existir una preocupación por parte de los productores con la calidad de la leche producida, ya que, hoy en día los consumidores están cada vez más preocupados por la calidad de los productos consumidos, además, el tema de la calidad es un requisito de la legislación y la industria. Para que esto suceda, se deben cumplir una serie de requisitos de Buenas Prácticas Agrícolas y Productivas. Así, el objetivo de la investigación fue verificar la calidad microbiológica y físico-química de la leche producida en la ciudad de Santana do Livramento-RS. Con los resultados obtenidos, podemos observar que en relación a los estándares físico-químicos, casi todos los productores cumplieron con los parámetros exigidos por la legislación. En relación al Conteo en Placa Estándar, el 73.33\% de los productores tienen estándares de conteo bajo con valores de 4.200 UFC / mL a 200.000 CFU / mL, lo que indica buenas condiciones de higiene y buenas prácticas en sus procesos. Se concluye que la leche de los productores analizados cumple, en su mayoría, los requisitos físico-químicos y microbiológicos establecidos por la legislación, lo que indica una preocupación por parte de estos productores con la calidad.
\end{abstract}

Palabras clave: Leche; Calidad; Microbiológico; Físico; Química.

\title{
1. Introdução
}

O leite é essencial à alimentação humana, sendo produzido em todo o mundo. A importância pode ser observada no ambiente produtivo e econômico mundial, principalmente em países considerados em desenvolvimento e em sistemas de agricultura familiar (FAO, 2016).

A produção de leite deverá crescer nos próximos 10 anos a uma taxa anual entre 2,1 e 2,9\%. O setor lácteo formal aumentou de 2,3\% em 2019 em relação a 2018, crescendo o consumo aparente per capita formal de 1,8\%, atingindo 124 litros/hab/ano, e o consumo per capita total, com a soma do leite não-inspecionado, aproximou-se dos 170 1/hab/ano (ANUÁRIO EMBRAPA, 2020).

Aproximadamente 150 milhões de famílias em todo o mundo estão envolvidas na produção de leite. Na maioria dos países em desenvolvimento, o leite é produzido nas propriedades contribuindo para a subsistência das famílias, e principalmente para a segurança alimentar e a nutrição. O leite fornece retornos relativamente rápidos para produtores familiares e é uma importante fonte de renda (FAO, 2019).

Segundo Carvalho et al. (2007), dada as perspectivas de produção futura, o investimento na produção em escala na implantação de tecnologias e, obviamente, na qualidade do leite é de extrema importância. Desse modo, segundo Rauta et al. (2016), tais ações são fundamentais para o crescimento e manutenção dessa importante atividade. Ainda, segundo os autores, os consumidores estão mais exigentes quanto aos produtos lácteos em geral, analisando desde a aparência dos derivados até seus parâmetros sanitários e nutricionais.

Entre 1998 e 2018 houve o crescimento de 62\% da produção mundial de leite, um aumento de 339 milhões de toneladas. O Brasil é o quarto maior produtor de leite no mundo, sendo superado pela Índia, estados Unidos e Paquistão (ANUÁRIO EMBRAPA, 2020). No entanto, a qualidade bacteriológica do leite produzido no Brasil é considerada insatisfatória e é um problema crônico difícil de resolver. Problemas relacionados à saúde da glândula mamária, higiene durante o processo de ordenha, eficácia práticas de limpeza e condições de armazenamento de leite cru estão intimamente ligados à baixa qualidade microbiológica do leite produzido em todo país (Capodifoglio et al., 2016). 
Segundo Martins et al. (2007), existe um aumento na demanda global para a produção de leite de alta qualidade, devido à exigência do consumidor por maior segurança alimentar (Monardes, 2004). Atributos como a composição química, as propriedades organolépticas (sabor, odor, aparência), o conteúdo microbiano, o número de células somáticas, a presença ou ausência de adulterantes e de contaminantes são, geralmente, referidos como parâmetros da qualidade do leite.

A composição e as propriedades físico-químicas do leite são de grande importância para a indústria de laticínios. Eles têm efeitos marcantes nas propriedades de processamento do leite e na qualidade dos produtos lácteos. Os efeitos da variação sazonal na composição do leite têm sido relatados por muitos pesquisadores e é claro que as concentrações de muitos constituintes e as propriedades físico-químicas variam ao longo do ano em diferentes graus (O’brien \& Guinee, 2011; Chen et al., 2014).

Para consistentemente fabricar laticínios de alta qualidade, processadores exigem leite cru de qualidade, que pode ser definido como um leite com composição completo, com níveis de proteína e gordura dentro do normal, livre de sabores e odores, livre de resíduos de medicamentos, sem adição de água e outros adulterantes, com baixa Contagem Bacteriana Total (CBT), e baixa Contagem de Células Somáticas (Murphy et al., 2016).

De acordo com Aernouts et al. (2011), a composição do leite produzido tem grande valor para o produtor de leite, determina o valor econômico de leite e fornece informações valiosas sobre o metabolismo da vaca correspondente, e é uma ferramenta de diagnóstico para monitorar a saúde individual das vacas e estado nutricional.

As propriedades físicas e químicas do leite podem ser alteradas por vários fatores relacionados às características dos sistemas de produção, como práticas alimentares, contaminação microbiana devido a práticas sanitárias, de ordenha e de resfriamento (Gabbi et al., 2013).

Segundo Holm et al. (2004) durante o processo de ordenha, o leite pode ser contaminado por três fontes principais: o equipamento de ordenha, a superfície do teto e de dentro do úbere. Quando o leite é coletado e armazenado em tanque a granel, a capacidade de resfriamento, a temperatura de retenção e o tempo de armazenamento influenciam a capacidade crescimento dos contaminantes.

Um melhor layout sanitário dos equipamentos, vacas mais limpas e mais eficientes, proporcionam a oportunidade para as fazendas produzirem leite cru com menos contaminação microbiana (Barbano; Santos, 2006).

Desse modo, o gerenciamento e práticas de higiene durante a ordenha, armazenamento e transporte de leite cru refrigerado desempenham um papel crítico sua qualidade bacteriológica (Guerreiro et al., 2005). O não cumprimento dos requisitos de higiene cria um sério risco para a saúde dos consumidores porque microbiologicamente o leite cru contaminado pode ser uma fonte de microrganismos patogênicos para o homem e de doenças transmitidas pelo leite (Piz-lukasik et al., 2015).

De acordo com O’Connell et al. (2016), testes microbianos como a Contagem Bacteriana Total (CBT) e Contagem Bacteriana Psicrotrófica (CBP) são utilizados para determinar a qualidade do leite cru e são influenciadas pelo tempo e temperatura de armazenamento. A Contagem Bacteriana Total (CBT) é o principal teste utilizado pelas indústrias de leite para avaliar a qualidade microbiológica do leite e quantifica as bactérias mesófilas aeróbias no leite (Paludetti et al., 2018).

A refrigeração do leite cru em fazendas e fábricas de processamento de laticínios mantém a qualidade do leite, reduzindo o crescimento de bactérias mesófilas (Samarzija et al., 2012). No entanto a refrigeração favorece o crescimento de bactérias psicrotróficas, particularmente o gênero Pseudomonas, principalmente quando as condições de armazenamento a frio são inadequadas. Entre o gênero Pseudomonas, a espécie Pseudomonas fluorescens mostrou importância considerável na deterioração do leite (Alves et al., 2018).

Segundo Mcphee et al. (2011) embora os microrganismos psicrotróficos sejam inativados por tratamentos térmicos comumente usados na indústria de laticínios, suas proteases extracelulares são geralmente termorresistentes e mantém suas 
atividades mesmo após a pasteurização do leite ou tratamento UHT. De acordo com Capodifoglio et al. (2016) esses microrganismos atuam na proteína do leite (k-caseína) causando uma desestabilização das micelas de caseína do leite, consequentemente ocorre a coagulação e formação de gel, impossibilitando o seu consumo.

Algumas bactérias têm capacidade de formar esporos que representam um desafio à qualidade do leite e produtos lácteos, algumas destas bactérias são capazes de sobreviver não apenas à pasteurização, mas também ao processo UHT e processos de secagem. Como tal, torna-se importante controlar a contaminação de bactérias por leite cru, o que levará a uma melhoria na qualidade de quaisquer produtos lácteos processado a partir de leite (Buehner et al., 2015).

As novas regras para produção e padrão de qualidade do leite cru refrigerado, do pasteurizado e do tipo A, foram determinadas pelas instruções normativas (INs) 76 e 77 em 2018. A IN 76 trata das características e da qualidade do produto na indústria já na IN 77, foram estabelecidos critérios para obtenção de leite de qualidade e seguro ao consumidor. O objetivo das novas regras é promover a competitividade do setor lácteo brasileiro em comparação com os mercados internacionais, e assim garantir renda e sustentabilidade para o setor em todo o país (MAPA, 2019).

Diante deste contexto o objetivo da pesquisa foi realizar uma análise das condições microbiológicas e físico-químicas do leite produzido pelos agricultores familiares da cidade de Santana do Livramento do estado do Rio Grande do Sul.

\section{Metodologia}

Foi realizada uma pesquisa de caráter quanti-qualitativa com produtores de leite da região da cidade de Santana do Livramento do estado do Rio Grande do Sul, Brasil (Yin, 2015). Foram realizadas coletas diretamente nas propriedades de 15 produtores de leite da cidade, nos meses de maio e junho de 2019. Os produtores foram identificados por letras e números (P1 ao P15). As análises microbiológicas e físico-químicas foram realizadas no Laboratório de microbiologia da Universidade Federal de Santa Maria (UFSM).

\subsection{Coleta de amostras}

As amostras foram coletadas diretamente dos resfriadores de leite, após serem agitadas e acondicionadas em frascos limpos contendo o conservante azidiol para Contagem Bacteriana Total (CBT) e em frasco estéril para as análises físicoquímicas. As amostras foram etiquetadas com nome do produtor, data, hora, e depois transportadas até o laboratório em caixa isotérmica contendo gelo reciclável e mantidas em temperatura de até $7^{\circ} \mathrm{C}$.

\subsection{Contagem Padrão em Placas (CPP)}

A Contagem Padrão em Placas (CPP) foi realizada de acordo com a Instrução Normativa $n^{\circ}$ 30, de 26 de junho de 2018 do Ministério de Agricultura, Pecuária e Abastecimento (MAPA) e o resultado foi expresso em UFC/mL. Bactérias do grupo mesófilas aeróbias foram quantificadas mediante plaqueamento em Ágar Padrão para Contagem (PCA), incubando-se a $35^{\circ} \mathrm{C} / 48$ horas (Brasil, 2018).

Análises físico-químicas do leite

As seguintes análises físico-químicas foram realizadas: determinação de gordura medida pelo método de Gerber, acidez por titulação com soda Dornic, a densidade, o Extrato Seco Desengordurado (ESD), proteína, lactose foram medidas em analisador ultrassônico de leite (Master Mini, AKSO) previamente calibrado. A crioscopia do leite do leite foi medida em Crioscópio ITR (Brasil, 2006; IAL, 2008). Os resultados foram analisados de acordo com a Instrução Normativa no 76 de 26 de Novembro de 2018 (Brasil, 2018). 


\subsection{Análise estatística}

Foi utilizado o software SPSS Statistics (SPSS, Chicago, IL, USA) para a análise estatística. Análise de variância (ANOVA) foi realizada e, ao serem detectadas diferenças significativas, foi aplicado teste de Tukey ao nível de 5\% de significância. Os resultados foram expressos em média \pm desvio padrão.

\section{Resultados e Discussão}

\subsection{Análises físico-químicas}

Os resultados das análises físico-químicas do leite cru refrigerado coletado na região da cidade de Santana do Livramento são apresentados nas Tabelas 1 e 2 e mostram que quase a totalidade dos produtores atende aos limites estabelecidos pela Instrução Normativa 76 do ano de 2018 para os parâmetros de gordura (93,33\%), Sólidos Não Gordurosos $(100 \%)$, proteína $(100 \%)$, lactose $(100 \%)$, densidade $(100 \%)$. Dentre os produtores apenas um produtor (P7) apresentou o teor de gordura abaixo do mínimo estabelecido pela legislação $(3 \mathrm{~g} / 100 \mathrm{~g})$ com um valor de 2,17g/100g. Valores semelhantes foram encontrados em uma pesquisa realizada por Silva et al. (2010) que avaliaram a qualidade físico-química e microbiológica do leite cru refrigerado em uma granja leiteira no Rio Grande Sul, onde todos os parâmetros estiveram dentro da legislação com uma pequena variação na gordura com valores de $2,9 \%$.

Como pode ser observado nas Tabelas 1 e 2, o parâmetro que mostrou maior variação foi o teor de gordura. Cabe salientar que todos os produtores dessa região utilizam o gado leiteiro da raça Holandesa, com exceção do produtor P3 que utiliza vacas Jersey, e em relação ao tipo de ordenha todos utilizam ordenhadeira mecânica.

Tabela 1 - Composição centesimal das amostras de leite de diferentes produtores da cidade de Santana do Livramento - RS.

\begin{tabular}{|c|c|c|c|c|c|}
\hline Produtor & $\begin{array}{l}\text { Gordura } \\
\text { (g/100g) }\end{array}$ & $\mathrm{SNG}^{*}(\mathrm{~g} / 100 \mathrm{~g})$ & Proteínas $(\mathrm{g} / 100 \mathrm{~g})$ & Cinzas $(\mathrm{g} / 100 \mathrm{~g})$ & Lactose $(\mathrm{g} / 100 \mathrm{~g})$ \\
\hline P1 & $3,69^{\mathrm{f}} \pm 0,01$ & $8,46^{\mathrm{cd}} \pm 0,11$ & $3,12^{\text {cde }} \pm 0,04$ & $0,71^{\mathrm{a}} \pm 0,01$ & $4,63^{\mathrm{efg}} \pm 0,06$ \\
\hline $\mathrm{P} 2$ & $4,08^{\mathrm{d}} \pm 0,04$ & $8,76^{\mathrm{bc}} \pm 0,06$ & $3,24^{\mathrm{bc}} \pm 0,02$ & $0,74^{\mathrm{a}} \pm 0,01$ & $4,79^{\mathrm{bc}} \pm 0,04$ \\
\hline P3 & $4,88^{\mathrm{b}} \pm 0,04$ & $9,23^{\mathrm{a}} \pm 0,04$ & $3,41^{\mathrm{a}} \pm 0,01$ & $0,78^{a} \pm 0,01$ & $5,04^{\mathrm{a}} \pm 0,02$ \\
\hline $\mathrm{P} 4$ & $4,14^{\mathrm{d}} \pm 0,01$ & $8,26^{\mathrm{d}} \pm 0,04$ & $3,05^{\mathrm{e}} \pm 0,01$ & $0,70^{\mathrm{a}} \pm 0,01$ & $4,51^{\mathrm{g}} \pm 0,02$ \\
\hline P5 & $3,52^{\mathrm{g}} \pm 0,03$ & $8,70^{\mathrm{bc}} \pm 0,03$ & $3,21^{\mathrm{bcd}} \pm 0,01$ & $0,73^{\mathrm{a}} \pm 0,01$ & $4,76^{\text {bcde }} \pm 0,02$ \\
\hline P6 & $3,99^{\mathrm{e}} \pm 0,01$ & $8,46^{\mathrm{cd}} \pm 0,03$ & $3,13^{\text {cde }} \pm 0,01$ & $0,71^{\mathrm{a}} \pm 0,00$ & $4,62^{\mathrm{efg}} \pm 0,01$ \\
\hline P7 & $2,17^{\mathrm{j}} \pm 0,00$ & $8,48^{\mathrm{cd}} \pm 0,05$ & $3,12^{\mathrm{cde}} \pm 0,01$ & $0,70^{\mathrm{a}} \pm 0,01$ & $4,65^{\text {cdefg }} \pm 0,03$ \\
\hline P8 & $3,65^{f} \pm 0,02$ & $8,77^{\mathrm{bc}} \pm 0,00$ & $3,22^{\mathrm{bcd}} \pm 0,03$ & $0,73^{\mathrm{a}} \pm 0,01$ & $4,78^{\mathrm{bcd}} \pm 0,04$ \\
\hline P9 & $5,57^{\mathrm{a}} \pm 0,01$ & $8,73^{\mathrm{bc}} \pm 0,03$ & $3,23^{\mathrm{bc}} \pm 0,01$ & $0,74^{\mathrm{a}} \pm 0,00$ & $4,76^{\mathrm{bcde}} \pm 0,01$ \\
\hline $\mathrm{P} 10$ & $3,11^{\mathrm{i}} \pm 0,01$ & $8,62^{\mathrm{bcd}} \pm 0,07$ & $3,18^{\mathrm{bcd}} \pm 0,02$ & $0,72^{\mathrm{a}} \pm 0,01$ & $4,72^{\text {bcdef }} \pm 0,04$ \\
\hline P11 & $3,95^{\mathrm{e}} \pm 0,01$ & $8,73^{\mathrm{bc}} \pm 0,01$ & $3,22^{\mathrm{bcd}} \pm 0,01$ & $0,73^{\mathrm{a}} \pm 0,01$ & $4,78^{\mathrm{bcd}} \pm 0,01$ \\
\hline P12 & $3,53^{\mathrm{g}} \pm 0,03$ & $8,40^{\mathrm{cd}} \pm 0,12$ & $3,10^{\mathrm{de}} \pm 0,04$ & $0,70^{\mathrm{a}} \pm 0,01$ & $4,59^{\mathrm{fg}} \pm 0,06$ \\
\hline P13 & $3,35^{\mathrm{h}} \pm 0,01$ & $8,50^{\text {bcd }} \pm 0,11$ & $3,13^{\text {cde }} \pm 0,04$ & $0,71^{\mathrm{a}} \pm 0,01$ & $4,65^{\text {cdefg }} \pm 0,06$ \\
\hline P14 & $4,31^{\mathrm{c}} \pm 0,01$ & $8,89^{a} \pm 0,07$ & $3,28^{\mathrm{b}} \pm 0,03$ & $0,75^{\mathrm{a}} \pm 0,01$ & $4,85^{\mathrm{b}} \pm 0,04$ \\
\hline P15 & $3,35^{\mathrm{h}} \pm 0,01$ & $8,47^{\mathrm{cd}} \pm 0,04$ & $3,12^{\text {cde }} \pm 0,01$ & $0,69^{\mathrm{a}} \pm 0,45$ & $4,64^{\text {cdefg }} \pm 0,02$ \\
\hline Legislação & Mín. 3,0 & Mín 8,4 & Mín 2,9 & - & Mín 4,3 \\
\hline
\end{tabular}

\footnotetext{
* Sólidos não gordurosos

Valores expressos em média \pm desvio padrão

Letras diferentes em uma mesma coluna indicam diferença significativa pelo teste de Tukey $(p<0.05)$.

Fonte: Autores (2021).
} 


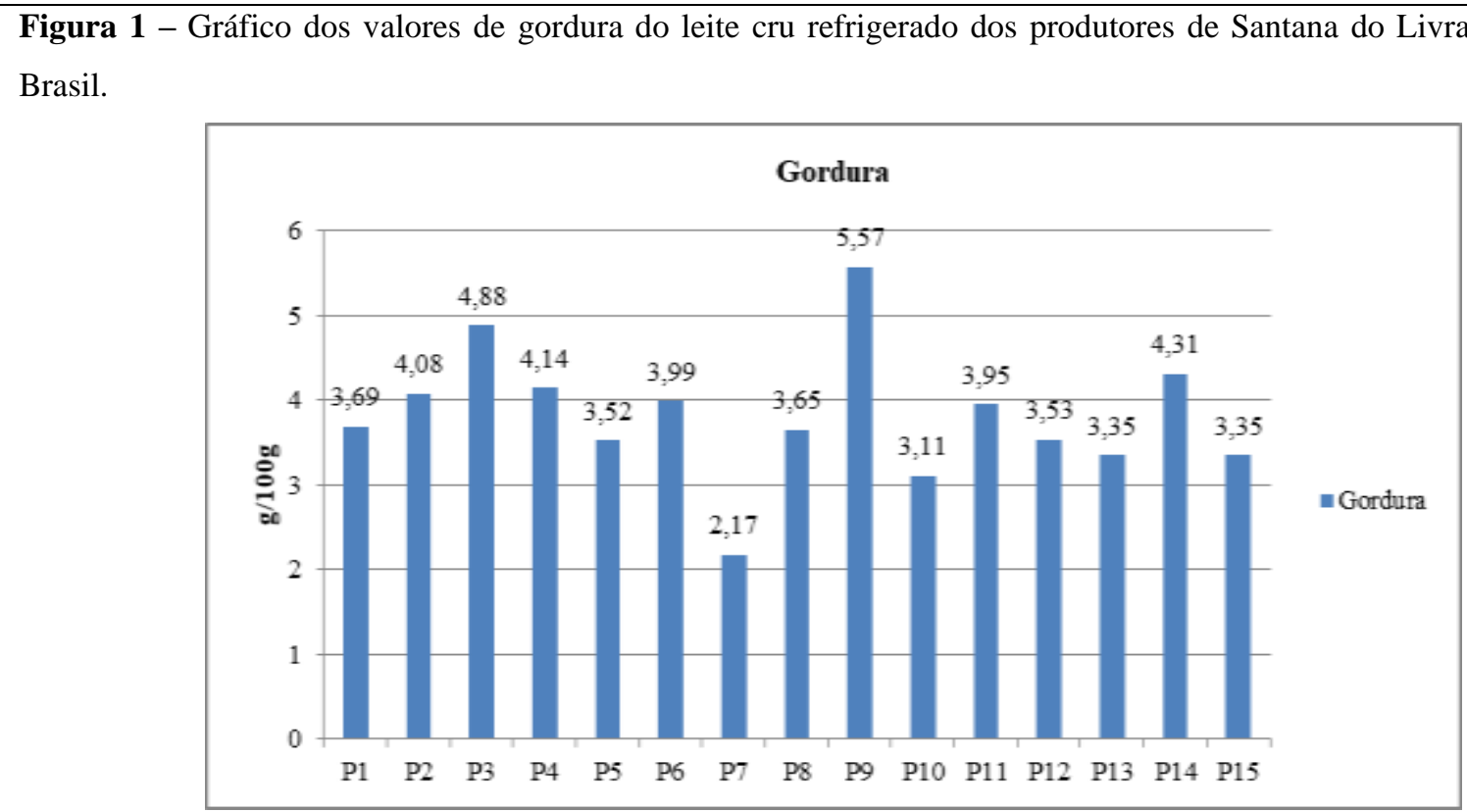

Fonte: Autores (2021).

O parâmetro que apresentou amostras fora do padrão da legislação foi o Ponto de Congelamento (PC) do leite, onde seis amostras $(40 \%)$ de produtores mostraram valores abaixo e acima do permitido $\left(-0,530^{\circ} \mathrm{H}\right.$ a $\left.-0,555^{\circ} \mathrm{H}\right)$, como mostra a Tabela 2 e a Figura 3. Podemos verificar na tabela que apenas um produtor apresentou o ponto de congelamento abaixo do mínimo exigido pela legislação, o produtor $\mathrm{P} 4 \operatorname{com}-0,526^{\circ} \mathrm{H}$, o que pode ser indicativo de adição de água no leite, mas de acordo com Zagorska e Ciprovica (2013), o ponto de congelamento do leite é influenciado por fatores como raça, estágio de lactação, idade, estado de saúde, qualidade e quantidade de ração, estação, região, tempo de ordenha e outros, eles relatam também que o resfriamento do leite causa agregação de sais solúveis e sua transferência para micelas de caseína ou glóbulos de gordura, e o ponto de congelamento pode variar dependendo da hora e temperatura das amostras analisadas.

Observou-se também valores de Ponto do Congelamento do leite acima do máximo estabelecido $\left(-0,562^{\circ} \mathrm{H}\right), \mathrm{P} 3(-$ $\left.0,600^{\circ} \mathrm{H}\right), \mathrm{P} 8\left(-0,557^{\circ} \mathrm{H}\right), \mathrm{P} 9\left(-0,568^{\circ} \mathrm{H}\right), \mathrm{P} 11\left(-0,559^{\circ} \mathrm{H}\right)$ e P14 $(-0,572)$, estes valores podem estar relacionados com o teor de sólidos no leite, já que a amostra P3 apresentou um teor de sólidos no valor de 9,23, ou até mesmo estes valores podem estar alterados devido à presença de substâncias adulterantes no leite. Em um estudo realizado por Zagorska e Ciprovica (2013), foram adicionadas substâncias adulterantes no leite como detergentes, formol, peróxido de hidrogênio, antibióticos e carbonato de sódio, e foi observada influência nos valores do Ponto de Congelamento do leite adicionado destas substâncias $-0,595^{\circ} \mathrm{H}$ (detergente), $-0,605^{\circ} \mathrm{H}$ (formol), $-0,554^{\circ} \mathrm{H}$ (peróxido de hidrogênio), $-0,558^{\circ} \mathrm{H}$ (antibiótico), $-0,594^{\circ} \mathrm{H}$ (carbonato de sódio). Segundo Becchi (2003), a água além de diluir os componentes do leite, pode representar um risco de contaminação, pois os microrganismos encontram um "habitat" ideal para seu desenvolvimento, com isso a primeira alteração físico-química que ocorre é o desenvolvimento da acidez. A acidez ocorre pelo desdobramento da lactose em ácido lático, portanto o estado de conservação influencia no Ponto de Congelamento do leite, pois a degradação da lactose pelos microrganismos faz com que aumente a acidez da amostra, como consequência haverá um aumento das substâncias solúveis no leite e o Ponto de Congelamento distancia-se de zero, isso pode ser observado nas amostras dos produtor P2 e P11 onde a acidez está em 0,20 g/100g de ácido lático e o Ponto de Congelamento está elevado - 0,559 e - $-0,562^{\circ} \mathrm{H}$ respectivamente.

Ainda analisando os parâmetros da legislação vigente observa-se que a acidez das amostras estava fora do padrão estabelecido, pois seis amostras de leite (40\%) dos produtores analisados apresentaram-se com valores abaixo e/ou acima do permitido $(0,14$ a $0,18 \mathrm{~g}$ de ácido lático/100mL). Os produtores $\mathrm{P} 2(0,20 \mathrm{~g}$ ácido lático/100 $\mathrm{mL}), \mathrm{P} 11(0,20 \mathrm{~g}$ ácido 
lático/100mL) e P12 (0,19g ácido lático/100 mL), o que indica que a acidez está alterada, isso pode ter ocorrido por falhas de Boas Práticas, um tempo elevado de armazenamento do leite no tanque de resfriamento.

Também pode-se observar na Tabela 2 que as amostras dos produtores P3, P6 e P15 apresentaram resultados abaixo do mínimo permitido pela legislação para acidez com valores de $0,12,013$ e 0,13 .

Tabela 2 - Parâmetros físico-químicos das amostras de leite de diferentes produtores da cidade de Santana do Livramento - RS.

\begin{tabular}{cccc}
\hline Produtores & $\begin{array}{c}\text { Densidade } \\
(\mathrm{g} / \mathrm{L})\end{array}$ & Acidez $(\mathrm{g} / 100 \mathrm{~g})$ & $\mathrm{PC}\left({ }^{\mathrm{o}} \mathrm{H}\right)$ \\
\hline P1 & $1029^{\mathrm{cd}}$ & $0,16^{\mathrm{bc}} \pm 0,01$ & $-0,533^{\mathrm{ab}} \pm 0,000$ \\
P2 & $1031^{\mathrm{a}}$ & $0,20^{\mathrm{a}} \pm 0,01$ & $-0,562^{\mathrm{ef}} \pm 0,005$ \\
P3 & $1031^{\mathrm{a}}$ & $0,12^{\mathrm{e}} \pm 0,01$ & $-0,600^{\mathrm{g}} \pm 0,003$ \\
P4 & $1028^{\mathrm{d}}$ & $0,17^{\mathrm{b}} \pm 0,01$ & $-0,526^{\mathrm{a}} \pm 0,003$ \\
P5 & $1030^{\mathrm{abc}}$ & $0,16^{\mathrm{bc}} \pm 0,01$ & $-0,553^{\mathrm{cde}} \pm 0,002$ \\
P6 & $1029^{\mathrm{cd}}$ & $0,13^{\mathrm{de}} \pm 0,01$ & $-0,540^{\mathrm{abc}} \pm 0,002$ \\
P7 & $1031^{\mathrm{a}}$ & $0,14^{\mathrm{cde}} \pm 0,01$ & $-0,530^{\mathrm{ab}} \pm 0,003$ \\
P8 & $1030^{\mathrm{acc}}$ & $0,14^{\mathrm{bcd}} \pm 0,01$ & $-0,557^{\mathrm{def}} \pm 0,005$ \\
P9 & $1029^{\mathrm{cd}}$ & $0,17^{\mathrm{b}} \pm 0,01$ & $-0,568^{\mathrm{ef}} \pm 0,002$ \\
P10 & $1030^{\mathrm{abc}}$ & $0,16^{\mathrm{bc}} \pm 0,01$ & $-0,544^{\mathrm{bcd}} \pm 0,002$ \\
P11 & $1030^{\mathrm{abc}}$ & $0,20^{\mathrm{a}} \pm 0,01$ & $-0,559^{\mathrm{def}} \pm 0,002$ \\
P12 & $1029^{\mathrm{cd}}$ & $0,19^{\mathrm{e}} \pm 0,01$ & $-0,532^{\mathrm{ab}} \pm 0,000$ \\
P13 & $1029^{\mathrm{cd}}$ & $0,18^{\mathrm{b}} \pm 0,01$ & $-0,539^{\mathrm{abb}} \pm 0,007$ \\
P14 & $1030^{\mathrm{abc}}$ & $0,16^{\mathrm{bc}} \pm 0,01$ & $-0,572^{\mathrm{ef}} \pm 0,005$ \\
P15 & $1029^{\mathrm{cd}}$ & $0,13^{\mathrm{de}} \pm 0,01$ & $-0,537^{\mathrm{ab}} \pm 0,002$ \\
\hline Limites (legislação) & $1028-1034$ & Mín. $0,14 \mathrm{a} 0,18$ & $-0,530 \mathrm{a}$ \\
& $(\mathrm{g} / \mathrm{L})$ & $\mathrm{g} \mathrm{de} \mathrm{lático} 100 \mathrm{~mL}$ & $-0,555^{\circ} \mathrm{H}$ \\
\hline
\end{tabular}

Valores expressos em média \pm desvio padrão $\quad \mathrm{PC}-$ Ponto de Congelamento

Letras diferentes em uma mesma coluna indicam diferença significativa pelo teste de Tukey $(\mathrm{p}<0.05)$.

Fonte: Autores (2021).

Figura 2 - Gráfico dos valores de acidez (g de ácido láctico/ $100 \mathrm{~mL}$ ) do leite cru refrigerado oriundo de propriedades familiares da cidade de Santana do Livramento - RS, Brasil.

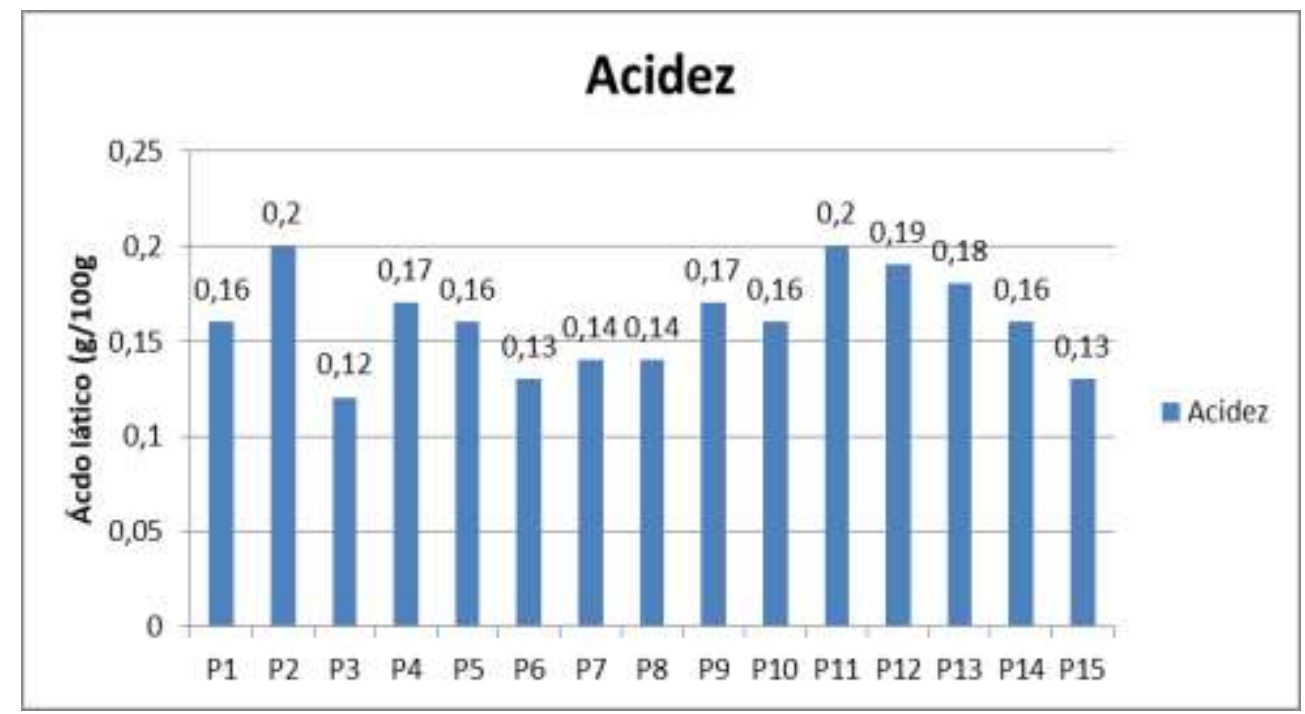

Fonte: Autores (2021). 
Figura 3 - Gráfico do ponto de congelamento $\left({ }^{\circ} \mathrm{H}\right)$ do leite cru refrigerado oriundo de propriedades familiares da cidade de Santana do Livramento - RS, Brasil.

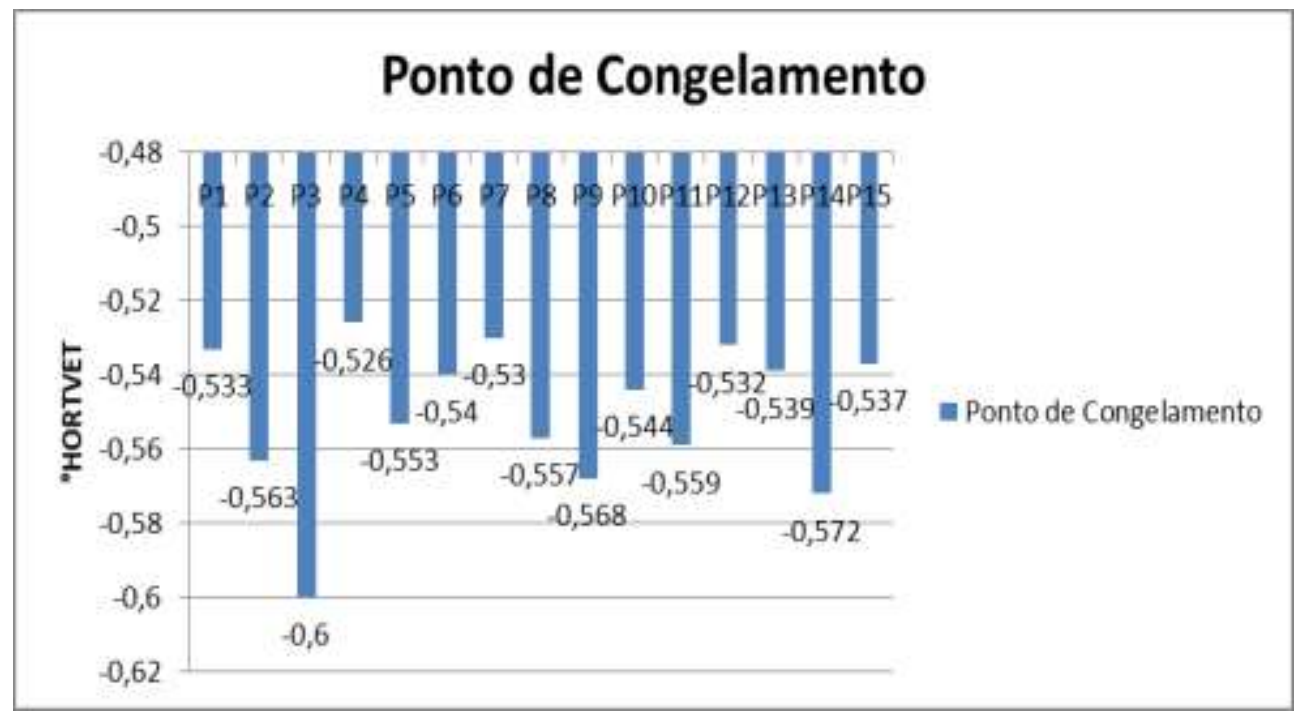

Fonte: Autores (2021).

\subsection{Contagem Padrão em Placas (CPP)}

Os resultados da Contagem Padrão em Placas (CPP) do leite coletados mostra a contagem total de bactérias no leite cru refrigerado. Contagens altas são indicativos de falhas nos procedimentos de higiene e Boas Práticas Agropecuárias durante a ordenha e de condições inadequadas de estocagem e transporte. Na Tabela 3 pode ser observado que a amostra oriunda de propriedades quatro $(26,66 \%)$ apresentaram contagens altas para CPP, que foram as amostras dos produtores P1 6.300.000 UFC/mL, P3 2.140.000 UFC/mL, P6 1.250.000 UFC/mL, P8 3.400.000 UFC/mL.

Tabela 3 - Contagem padrão em placas (CPP) das amostras de leite de diferentes produtores da região da Campanha do Rio Grande do Sul.

\begin{tabular}{cc}
\hline Produtores & CPP $(\mathrm{UFC} / \mathrm{mL})$ \\
\hline P1 & $6,3 \times 10^{6 \mathrm{ef}} \pm 16,97$ \\
P2 & $4,2 \times 10^{3 \mathrm{fg}} \pm 2,83$ \\
P3 & $2,14 \times 10^{6 \mathrm{a}} \pm 3,53$ \\
P4 & $3,3 \times 10^{4 \mathrm{fg}} \pm 5,66$ \\
P5 & $1,3 \times 10^{5 \mathrm{bc}} \pm 4,24$ \\
P6 & $1,25 \times 10^{6 \mathrm{bcd}} \pm 18,38$ \\
P7 & $8,6 \times 10^{4 \mathrm{de}} \pm 0,71$ \\
P8 & $3,4 \times 10^{6} \mathrm{fg}^{\mathrm{g}} \pm 5,65$ \\
P9 & $1,36 \times 10^{5 \mathrm{~b}} \pm 19,79$ \\
P10 & $2,0 \times 10^{5 \mathrm{~g}} \pm 4,24$ \\
P11 & $1,2 \times 10^{5 \mathrm{bcd}} \pm 11,31$ \\
P12 & $9,4 \times 10^{4 \mathrm{cde}} \pm 10,60$ \\
P13 & $4,0 \times 10^{4 \mathrm{fg}} \pm 0,00$ \\
P14 & $8,7 \times 10^{3 \mathrm{de}} \pm 7,79$ \\
P15 & $3,0 \times 10^{5 \mathrm{de}} \pm 7,07$ \\
\hline
\end{tabular}

Valores expressos em média \pm desvio padrão

Letras diferentes em uma mesma coluna indicam diferença significativa pelo teste de Tukey $(\mathrm{p}<0.05)$. Fonte:

Autores (2021) 
Segundo Zhu et al. (2019), altas contagens bacterianas sugerem a existência de contaminação microbiana. O interior do úbere subsequente à síntese, a parte externa do úbere e a superfície do equipamento de processamento e armazenamento de leite são as fontes de bactérias.

De acordo com Paludetti et al. (2017) o resfriamento do leite e o armazenamento refrigerado são necessários após ordenha para reduzir as taxas de crescimento bacteriano. De acordo com Holm et al. (2004), é necessário resfriar o leite rapidamente (abaixo de $6^{\circ} \mathrm{C}$ ) para evitar a multiplicação de microrganismos, especialmente psicrotróficos, que podem crescer sob temperaturas de refrigeração.

Segundo Vargas et al. (2013), o leite com elevada CPP representa risco para a saúde do consumidor, pelo potencial de veiculação de microrganismos e toxinas microbianas. Não conformidades com requisitos de higiene institui um sério perigo para a saúde dos consumidores porque microbiologicamente leite cru contaminado pode ser fonte de microrganismos patogênico para humanos e doenças transmitidas pelo leite. A ocorrência de doenças transmitidas pelo leite é mais frequente em humanos que consomem leite cru do que naqueles que consomem leite pasteurizado.

Cabe salientar que contagens baixas de bactérias no leite cru são indícios de boas práticas durante a ordenha e que este produtor atende os requisitos de higiene em seus processos. Pode-se observar que alguns produtores estão com resultado com contagens baixas (Tabela 3), os produtores P2 4200 UFC/mL, P4 33000 UFC/mL, P5 130.000 UFC/mL, P7 86.000 UFC/mL, P9 136.000 UFC/mL, P10 200.000, P11 118.000 UFC/mL, P12 94.000 UFC/mL, P13 40.000 UFC/mL, P14 8.700 UC/mL, P15 86.000 UFC/mL. Alguns destes valores podem ser comparados com padrões internacionais para Contagem Bacteriana Total (CBT), de acordo com o apêndice III, seção IX, capítulo I do Regulamento (CE) no 853/2004 do Parlamento Europeu Parlamento (União Europeia, 2004a) e do o Conselho de 29 de abril de 2004 (União Europeia, 2004b), contagem bacteriana e contagem de células somáticas no leite cru de vaca não devem exceder 100.000 e $400.000 / \mathrm{mL}$, respectivamente. Ambos as contagens são medidas no leite cru antes do processamento, e seus valores indicam o estado de saúde glândula mamária.

A legislação brasileira para leite que estabelece o Regulamento Técnico de Qualidade e Identidade do leite cru refrigerado é a Instrução Normativa 76 de 26 de Novembro de 2018 (Brasil, 2018), que determina os padrões físico-químicos do leite bem como os padrões de Contagem Padrão em Placas (CPP) e Contagem de Células Somáticas (CCS) máximas para o leite na propriedade. Em seu artigo $7^{\circ}$ ela determina que o leite cru refrigerado de tanque individual ou de uso comunitário deve apresentar médias geométricas trimestrais de Contagem Padrão em Placas de no máximo 300.000 UFC/mL (trezentas mil unidades formadoras de colônia por mililitro) e de Contagem de Células Somáticas de no máximo 500.000 CS/mL (quinhentas mil células por mililitro). Portanto para que estes pudessem ser enquadrados de acordo com esta legislação deveriam ter três meses de coletas de cada produtor. Outra questão importante e determinada pela Instrução Normativa 77 de 26 de Novembro de 2018, é que o produtor que não atender a média geométrica trimestral de 300.000 UFC/mL não poderá entregar mais o leite para indústria.

Segundo Brasil (2018), o estabelecimento deve interromper a coleta do leite na propriedade que apresentar, por três meses consecutivos, resultado de média geométrica fora do padrão estabelecido em Regulamento Técnico de Identidade e Qualidade do leite cru refrigerado para Contagem Padrão em Placas - CPP. Para restabelecimento da coleta do leite, deve ser identificada a causa do desvio, adotadas as ações corretivas e apresentado 1 (um) resultado de análise de Contagem Padrão em Placas - CPP - dentro do padrão, emitido por laboratório da RBQL.

\section{Conclusão}

Concluiu-se com a pesquisa que o leite cru refrigerado produzido em propriedades familiares na região da Campanha do Rio Grande do Sul em sua maioria atende os requisitos físico-químicos estabelecidos pela legislação. Em relação a Contagem Bacteriana Total (CBT) a maioria dos produtores possui contagens baixas de microrganismos, o que é um indicativo 
de higiene e Boas Práticas de Fabricação durante a ordenha e estocagem do produto, o que mostra uma preocupação com a qualidade do leite produzido.

Considerando-se os resultados obtidos sugere-se a necessidade de ações de extensão para melhorar a qualidade do leite produzido na região da Campanha do Rio Grande do Sul e que novos estudos sobre tal realidade sejam realizados para fomentar o desenvolvimento regional e contribuir com a ciência.

\section{Referências}

Aernouts, B., Polshin, E., Lammertyn, J., \& Saeys, W. (2011). Visible and near-infrared spectroscopic analysis of raw milk for cow health monitoring: Reflectance or transmittance? Journal of Dairy Science Vol. 94 No. 11.

Alves, M. P., Salgado, R. L., Eller, M. R., Dias, R. S., De Paula, S. O., \& Carvalho, A. F. (2018). Temperature modulates the production and activity of a metalloprotease from Pseudomonas fluorescens in milk. Journal of Dairy Science Vol. 101 No. 2.

Barbano, D. M., \& Santos, M. V. (2006). Influence of Raw Milk Quality on Fluid Milk Shelf Life. Journal of Dairy Science 89.

Becchi, C. S. Estudo do Índice Crioscópico do Leite Tipo B “In natura”, produzido na bacia leiteira no vale do Taquari-RS (Dissertação de Mestrado). (2003) Universidade Federal do Estado do Rio Grande do Sul, 106p.

Brasil, Ministério de Estado da Agricultura, Pecuária e Abastecimento. INSTRUÇÃO NORMATIVA No 76, DE 26 DE NOVEMBRO DE 2018. Ficam aprovados os Regulamentos Técnicos que fixam a identidade e as características de qualidade que devem apresentar o leite cru refrigerado, o leite pasteurizado e o leite pasteurizado tipo A, na forma desta Instrução Normativa e do Anexo Único.

Brasil, Ministério de Estado da Agricultura, Pecuária e Abastecimento. INSTRUÇÃO NORMATIVA No 77 , DE 26 DE NOVEMBRO DE 2018. Ficam estabelecidos os critérios e procedimentos para a produção, acondicionamento, conservação, transporte, seleção e recepção do leite cru em estabelecimentos registrados no serviço de inspeção oficial, na forma desta Instrução Normativa e do seu Anexo.

Brasil, Ministério de Estado da Agricultura, Pecuária e Abastecimento. INSTRUÇÃO NORMATIVA N 30 , DE 26 DE JUNHO DE 2018. Ficam estabelecidos como oficiais os métodos constantes do Manual de Métodos Oficiais para Análise de Alimentos de Origem Animal, indexado ao International Standard Book Number (ISBN) sob o número 978-85-7991-111-8, disponível no sítio eletrônico do MAPA, para realização de ensaios em amostras de produtos de origem animal, oriundas dos programas e controles oficiais do MAPA, cuja adoção é compulsória pelos laboratórios integrantes da Rede Nacional de Laboratórios Agropecuários do Sistema Unificado de Atenção a Sanidade Agropecuária. Publicado em: 13/07/2018 | Edição: 134 | Seção: 1 | Página: 9.

Buehner, K. P., Anand, S., \& Djira, G. D. (2015). Prevalence of thermoduric bacteria and spores in nonfat dry milk powders of Midwest origin. Journal of Dairy Science 98(5).

Capodifoglio, E., Vidal, A M. C., Lima, J. A. S., Bortoletto, F., D’abreu, L. F., Gonçalves, Ac. S., Vaz, A. C. N., Balieiro, J. C. C., \& Neto, A. S. (2016). Lipolytic and proteolytic activity of Pseudomonas spp. Isolated during milking and storage of refrigerated raw milk. Journal of Dairy Science 99(7).

Carvalho, M. P., Martins, P. C., Wright, J. T. C., \& Spers, R. G. (2007). Cenários para o leite no Brasil em 2020. Juiz de Fora: EMBRAPA Gado de Leite.

Chen, B., Lewis, M. J., \& Grandison, A. S. (2014). Effect of seasonal variation on the composition and properties of raw milk destined for processing in the UK. / Food Chemistry 158, 216-223. http://dx.doi.org/10.1016/j.foodchem.2014.02.118.

European Union. 2004a. Regulation (EC) No 852/2004 of the European Parliament and of the Council of 29 April 2004-On the hygiene of foodstuffs. Off. J. L139:1-54.

European Union. 2004b. Regulation (EC) No 853/2004 of the European Parliament and of the Council of 29 April $2004-$ Laying down specific hygiene rules for food of animal origin. Off. J. L139:55-205.

Food And Agriculture Organization Of The United Nations (FAO). (2016). Dairy Production and Products - Milk Production.

Food And Agriculture Organization Of The United Nations (FAO). (2019). Dairy Production and Products - Milk Production.

Gabbi, A. M., Mcmanusc. M., Silva, A. V., Marques, L. T., Zanela,M. B., Stumpf, M. P., \& Fischer, V. (2013). Typology and physical-chemical characterization of bovine milk produced with different productions strategies. Agricultural Systems 121 (2013) 130-134.

Guerreiro, P. K., Machado, M. R. F., Braga, G. C., Gasparino, E., \& Franzener, A. S. M. (2005). Qualidade microbiológico do leite em função de técnicas profiláticas no manejo de produção. Ciênc. agrotec., 29(1), 216-222.

Holm, C., Jepsen, L., Larsen, M., \& Jespersen, L. (2004). Predominant Microflora of Downgraded Danish Bulk Tank Milk. Journal of Dairy Science 87(5).

Karlsson, M. A., Langton, M., Innings, F., Wikstrom, M., \& Lundh, A. S. (2017). Short communication: Variation in the composition and properties of Swedish raw milk for ultra-high-temperature processing. Journal of Dairy Science. 100(4).

Martins, P. R. G., Fisher, V., Ribeiro, M. E. R., Gomes, J. F., Stumpf, W., \& Zaneka, M. B. (2007) Produção e qualidade do leite em sistemas de produção da região leiteira de Pelotas, RS, Brasil. Ciência Rural, 37(1), 212-217.

McPhee, J. D., \& Griffithis, M. W. (2011). Psychrotrophic bacteria. Pseudomonas spp. Pages 379-383 in Encyclopedia of Dairy Sciences. J. W. Fuquay, P. F. Fox, and P. L. H. McSweeney, ed. Academic Press, Cambridge, MA. 
Research, Society and Development, v. 10, n. 6, e24310615561, 2021

(CC BY 4.0) | ISSN 2525-3409 | DOI: http://dx.doi.org/10.33448/rsd-v10i6.15561

Mapa. Ministério da Agricultura, Pecuária e Abastecimento. (2018) Projeções do Agronegócio: Brasil 2017/18 a 2027/28 projeções de longo prazo / Ministério da Agricultura, Pecuária e Abastecimento. Secretaria de Política Agrícola: MAPA/ACE, 112 p.

Murphy, S. C., Martin, N. H., Barbano, D. M., \& Wiedmann, M. (2016). Influence of raw milk quality on processed dairy products: How do raw milk quality test results relate to product quality and yield? Journal of Dairy Science 99(12)

O'Brien, B., \& Guinee, T. P. Seasonal effects on processing properties of cows' milk. (2011). Pages 598-606 in Encyclopedia of Dairy Sciences. (2nd ed.) J. W. Fuquay, P. F. Fox, and P. L. H. McSweeney, ed. Academic Press.

O’Connell, A., Ruegg, P. L., Jordam, K., O’brien, B., \& Gleeson, D. (2016). The effect of storage temperature and duration on the microbial quality of bulk tank milk. Journal of Dairy Science. 99(5).

Paixão, M. G. (2013). Caracterização de propriedades leiteiras localizadas na região do Alto Rio Grande e fatores associados a qualidade higiênico-sanitária do leite no período de 2011-2012 (Dissertação de Mestrado), Universidade Federal de Lavras - MG, 237p.

Paludetti, L. F., Kelly, A. L., O'brienb., Jordan, K. , \& Gleeson, D. (2018). The effect of different precooling rates and cold storage on milk microbiological quality and composition. Journal of Dairy Science 101(3).

Piz-Lukasik, R., Paszkiewicz, W., Tatara, M. R., Broddzki, P., \& Belkot, Z. (2015). Microbiological quality of milk sold directly from producers to consumers. Journal of Dairy Science Vol. 98 No. 7.

Samarzija, D., Zamberlin, S., \& Pogacic, T. (2012). Psychrotrophic bacteria and milk and dairy products quality. Mljekarstvo 62:77-95.

Silva, T. F. (2011). Qualidade do leite de um rebanho Gir do estado do Espírito Santo (Tese de Doutorado), Universidade Estadual do Norte Fluminense Dacy Ribeiro, Campo dos Gyitacazes, $60 \mathrm{p}$.

Vargas, D. P., Nornberg, J. L., Mello, R. O., Sheibler, R. B., Milani, M. P, \& Mello, F. C. B. (2013). Correlações entre contagem bacteriana total e parâmetros de qualidade do leite. R. bras. Ci. Vet., 20(4), 241-247.

Yin, R.K. (2015). O estudo de caso. Bookman.

Zagoeska, J., \& Ciprovia, I. (2013). Evaluation of Factors Affecting Freezing Point of Milk. International Journal of Biological, Biomolecular, Agricultural, Food and Biotechnological Engineering 7(2). 